\title{
Low frequency of enterohemorrhagic, enteroinvasive and diffusely adherent Escherichia coli in children under 5 years in rural Mozambique: a case-control study
}

Marcelino Garrine ${ }^{1,2}$, Glória Matambisso', Nélio Nobela¹, Delfino Vubil', Sérgio Massora', Sozinho Acácio 1,3, Tacilta Nhampossa ${ }^{1,3}$, Pedro Alonso ${ }^{1,4}$ and Inácio Mandomando ${ }^{1,3^{*}}$ (i)

\begin{abstract}
Background: Diarrheagenic Escherichia coli (DEC) are among the leading pathogens associated with endemic diarrhea in low income countries. Yet, few epidemiological studies have focused the contribution of enterohemorrhagic E. coli (EHEC), enteroinvasive E. coli (EIEC) and diffusely adherent E. coli (DAEC).

Methods: We assessed the contribution of EHEC, EIEC and DAEC isolated from stool samples from a case-control study conducted in children aged < 5 years in Southern Mozambique between December 2007 and November 2012. The isolates were screened by conventional PCR targeting stx 1 and stx2 (EHEC), ial and ipaH (EIEC), and daaE (DAEC) genes.

Results: We analyzed 297 samples from cases with less-severe diarrhea (LSD) matched to 297 controls, and 89 samples from cases with moderate-to-severe diarrhea (MSD) matched to 222 controls, collected between November 3, 2011 and November 2, 2012. DEC were more common among LSD cases (2.7\%, [8/297] of cases vs. 1.3\% [4/297] of controls; $p=0.243])$ than in MSD cases (0\%, [0/89] of cases vs. 0.4\%, [1/222] of controls; $p=1.000)$. Detailed analysis revealed low frequency of EHEC, DAEC or EIEC and no association with diarrhea in all age strata. Although the low frequency, EIEC was predominant in LSD cases aged $24-59$ months (4.1\% for cases vs. 0\% for controls), followed by DAEC in similar frequency for cases and controls in infants (1.9\%) and lastly EHEC from one control. Analysis of a subset of samples from previous period (December 10, 2007 and October 31, 2011) showed high frequency of DEC in controls compared to MSD cases $(16.2 \%$, $[25 / 154]$ vs. $11.9 \%,[14 / 118], p=0.383$, respectively). Among these, DAEC predominated, being detected in $7.7 \%$ of cases vs. $17.6 \%$ of controls aged $24-59$ months, followed by EIEC in $7.7 \%$ of cases vs. $5.9 \%$ of controls for the same age category, although no association was observed. EHEC was detected in one sample from cases and two from controls.

Conclusions: Our data suggests that although EHEC, DAEC and EIEC are less frequent in endemic diarrhea in rural Mozambique, attention should be given to their transmission dynamics (e.g. the role on sporadic or epidemic diarrhea) considering that the role of asymptomatic individuals as source of dissemination remains unknown.
\end{abstract}

Keywords: Diarrhea, Diarrheagenic Escherichia coli pathotypes, PCR, Children

\footnotetext{
* Correspondence: inacio.mandomando@manhica.net

'Centro de Investigação em Saúde de Manhiça (CISM), Maputo, Mozambique

${ }^{3}$ Instituto Nacional de Saúde (INS), Ministério da Saúde, Maputo,

Mozambique

Full list of author information is available at the end of the article
}

(c) The Author(s). 2020 Open Access This article is licensed under a Creative Commons Attribution 4.0 International License, which permits use, sharing, adaptation, distribution and reproduction in any medium or format, as long as you give appropriate credit to the original author(s) and the source, provide a link to the Creative Commons licence, and indicate if changes were made. The images or other third party material in this article are included in the article's Creative Commons licence, unless indicated otherwise in a credit line to the material. If material is not included in the article's Creative Commons licence and your intended use is not permitted by statutory regulation or exceeds the permitted use, you will need to obtain permission directly from the copyright holder. To view a copy of this licence, visit http://creativecommons.org/licenses/by/4.0/. The Creative Commons Public Domain Dedication waiver (http://creativecommons.org/publicdomain/zero/1.0/) applies to the data made available in this article, unless otherwise stated in a credit line to the data. 


\section{Background}

Diarrheal illness is one of the major cause of morbidity and mortality among children less than 5 years of age, accounting for 526,000 of the 5.942 millions of deaths globally [1]. Studies on diarrheal diseases from South America and Africa have reported prevalence of bacterial pathogens ranging between 27 and 56\%, with diarrheagenic Escherichia coli (DEC) being one of the most frequent identified pathogen in children with diarrhea [2-5]. DEC have been traditionally classified in six groups based on their clinical, epidemiological and virulence traits: enterotoxigenic E. coli (ETEC), enteropathogenic $E$. coli (EPEC), enteroinvasive E. coli (EIEC), enteroaggregative $E$. coli (EAEC), diffusely adherent $E$. coli (DAEC) and enterohemorrhagic E. coli (EHEC) [6-8]. Among these, ETEC, EPEC and EAEC have consistently been associated with endemic diarrheal, while EHEC is often associated with outbreaks [8]. In contrast, the epidemiology and the role of DAEC on diarrheal remain unclear in most developing countries [9, 10]; while EIEC has been reported sporadically with low frequency in Africa [4, 11].

In Mozambique, despite the trend of diarrheal decline over the years (1997-2011), it remains among the major causes of morbidity and mortality in children aged less than 5 years [12], particularly in Manhiça district [13]. Studies reporting the occurrence of DEC in Mozambique remain scarce, and often focus on molecular screening of the three most common pathotypes (EAEC, ETEC and EPEC) $[5,11$, 14-17] rather than all DEC. As part of the Global Enteric Multicenter Study (GEMS) we have previously demonstrated that ETEC, producing stable toxin (ST-ETEC) was the only E. coli pathotype associated to moderate-to-severe diarrhea (MSD) [16] and less-severe diarrhea (LSD) [17] in toddlers (12-23 months) in Mozambique. However, GEMS did not assess the potential role of less common pathotypes (EIEC, EHEC and DAEC). Therefore, in this study, we investigated the contribution of those pathotypes on diarrheal etiology in children aged $<5$ years enrolled in the GEMS in Manhiça, southern Mozambique between December 10, 2007 and November 2, 2012.

\section{Methodology}

\section{Study site description}

The study was conducted by the Manhiça Health Research Centre (Centro de Investigação em Saúde de Manhiça - CISM), in Manhiça district, a rural area in Maputo Province, southern Mozambique. The district is located approximately $80 \mathrm{~km}$ north of Maputo city with two distinct seasons, rainy and hot season from November to April and dry and cool season from May to October, as detailed elsewhere $[18,19]$. The CISM has been running a continuous Demographic Surveillance System (DSS) for vital events and migrations since 1996 [18], currently covering the entire Manhiça district with an estimated population of 183,000 inhabitants in 43,000 households with two regular visits a year to update demographic events (migration, births, deaths, etc.).

\section{Study design}

We analyzed a subset of $E$. coli isolates collected under the GEMS protocol conducted between two distinct periods, that aimed to quantify the burden, etiology and sequelae of diarrhea in sub-Saharan Africa and South Asia [16]. The first period (December 10, 2007 and October $31,2011)$ comprised only the enrolment of children with MSD and respective controls without diarrhea [16], while the second one (November 3, 2011 and November 2 , 2012) comprised two parallel case-control studies, one assessing MSD and the other LSD; each with their respective controls [17]. In the GEMS study, children less than 5 years with diarrhea ( $\geq 3$ loose stools within the previous $24 \mathrm{~h}$ ) belonging to the catchment area under DSS who sought care at the sentinel health centers (SHCs) were assessed for study criteria and enrolled in LSD or MSD group. MSD was defined as a new (onset after $\geq 7$ diarrhea-free days) and acute (onset within the previous 7 days) diarrheal episode presenting one of the following criteria: sunken eyes, loss of skin turgor, intravenous hydration administered or prescribed, dysentery, or hospitalization [20]. LSD was defined as a new acute diarrhea case seen at SHCs that did not meet the definition of MSD. For each case, 1-3 community based controls (children free of diarrhea in the last 7 days) were enrolled matched by age stratum (infants [0-11 months], toddlers [12-23 months] and young children [24-59 months]), neighborhood and gender as described elsewhere [20]. At enrolment, each participant provided fresh stool that was placed in cold chain and transport media according to the protocol. If antibiotics were to be administered to participants with diarrhea before stool was produced, we obtained two rectal swabs for bacterial culture pending passage of the whole stool for the remaining assays [20].

\section{Specimen processing for pathogen detection}

In GEMS protocol, the stool samples from cases and controls were assessed for numerous enteropathogens (bacterial, protozoal and viral agents) using microbiological and molecular methods $[17,21]$. For E. coli isolation, stool samples were plated onto MacConkey (MAC) agar and incubated at $37^{\circ} \mathrm{C}$ for $18-24 \mathrm{~h}$. Afterward, putative lactose-fermenting bacterial colonies resembling $E$. coli were picked and tested using Motility Indole Ornithine medium. Up to 3 lactose and indole positive $E$. coli colonies per sample were selected and stored at $-80{ }^{\circ} \mathrm{C}$ in single colony for further analysis [21]. In GEMS protocol, the $E$. coli colonies were analyzed by multiplex PCR that targeted only for ETEC, EAEC and EPEC [21]. 
Therefore, in this investigation, the E. coli colonies from GEMS were screened by conventional PCR targeting additional pathotypes of DEC as EHEC (stx 1 and stx2), DAEC (daaE) and EIEC (ial and ipaH). Briefly, the three putative E. coli colonies isolated from stools in GEMS study were retrieved onto MAC and incubated at $37^{\circ} \mathrm{C}$ for $18-24 \mathrm{~h}$. Afterward, the E. coli colonies from same stool were pooled, the DNA extracted [21] and analyzed by multiplex PCRs using primers previously designed for detection of ial [22], ipaH [23], daaE [24], stx1 and stx2 genes [21]. We performed two multiplex PCRs; the first one detected genes ial, ipaH and daaE and the second one the genes st $x 1$ and st $x 2$. For the first multiplex, $3 \mu \mathrm{l}$ of DNA template was added to the PCR mix containing 12.5 $\mu$ l of PCR Mix 2X (Qiagen), $5 \mu$ l of Q-solution 10X (Qiagen), $0.5 \mu \mathrm{l}$ of $10 \mu \mathrm{M}$ of each primer and $1.5 \mu \mathrm{l}$ of RNase-free water to a final volume of $25 \mu$ l. The second multiplex contained: $12.5 \mu \mathrm{l}$ of PCR Mix 2X (Qiagen), $5 \mu \mathrm{l}$ of Q-solution 10X (Qiagen), $0.2 \mu \mathrm{l}$ of $25 \mu \mathrm{M}$ of each primer, $3.7 \mu \mathrm{l}$ of RNase-free water and $3 \mu \mathrm{l}$ of DNA template to a final volume of $25 \mu \mathrm{l}$. A single cycling protocol was applied for both multiplex, with following parameters: preheating at $95^{\circ} \mathrm{C}$ for $15 \mathrm{~min}$; and 35 cycles of denaturation at $94^{\circ} \mathrm{C}$ for $30 \mathrm{~s}$, annealing at $57^{\circ} \mathrm{C}$ for $90 \mathrm{~s}$, elongation at $72{ }^{\circ} \mathrm{C}$ for $90 \mathrm{~s}$; with final extension at $72{ }^{\circ} \mathrm{C}$ for $10 \mathrm{~min}$ in an Eppendorf Mastercycler Gradient thermal cycler (Eppendorf, Hamburg, Germany). The amplification products were separated through a $2 \%$ agarose gel stained with ethidium bromide. The $1-\mathrm{kb}$ plusA $100-$ bp DNA ladder (Bio-Rad) was used as a molecular size marker in gel.

\section{Statistical analysis}

The statistical analyses were performed using STATA version 14.1 (StataCorp LP, College Station, Texas, USA). We assessed associations of MSD and LSD with each pathotype (EHEC, EIEC e DAEC) using Chi-squared test or Fisher's exact test, as appropriate. We deemed $p$-value of 0.05 or lower to be statistically significant.

\section{Results}

Diarrheagenic Escherichia coli isolated between November 3, 2011 and November 2, 2012

We analyzed 297 stools samples from cases with LSD matched to 297 controls (children without diarrhea), and
89 stool samples from cases with MSD matched to 222 controls, collected between November 3, 2011 and November 2, 2012. Among the cases with LSD, 120 children aged 12-23 months, 104 were infants, and 73 were young children (Table 1). In contrast, the MSD study showed that, diarrhea was most frequent in infants (42 cases matched to 99 controls), followed in children aged 12-23 months (29 cases matched to 79 controls) and lastly in young children (18 cases matched to 44 controls). We also found that diarrhea was more frequently reported in male children than in female children, both in LSD (54.2\%, 161/ 297) and in the MSD study (64.2\%, 57/89).

DEC were more common among LSD cases $(2.7 \%$, [8/ 297] of cases vs. $1.3 \%$ [4/297] of controls; $p=0.243]$ ) than in MSD cases $(0 \%,[0 / 89]$ of cases vs. $0.4 \%,[1 /$ 222 ] of controls; $p=1.000)$. Detailed analysis of DEC circulation for the above period showed a low frequency of EHEC, EIEC and DAEC in all age strata with no significant association with neither LSD nor MSD. Although the low frequency of pathotypes among cases in the LSD group, EIEC was predominant in children aged 24-59 months $(4.1 \%$ [3/73] for cases vs. $0 \%$ for controls). This was followed by DAEC in children from 0-11 months (1.9\% [2/104] for cases vs. 1.9\% [2/104] for controls) and lastly EHEC being isolated in one sample from control (Table 1). Among the MSD group, DAEC was only detected in one sample from control (0-11 months), while EIEC and EHEC were absent.

\section{Diarrheagenic Escherichia coli isolated between December 10, 2007 and October 31, 2011}

The analysis of a subset of E. coli (118 from cases with MSD and from 154 matched controls) isolated between December 10, 2007 to October 31, 2011 revealed remarkable variation of pathotypes EHEC, EIEC and DAEC frequencies when compared to the period between November 3, 2011 and November 2, 2012. We observed high frequency of DEC in controls compared to MSD cases $(16.2 \%$, [25/154] vs. $11.9 \%$, [14/118], $p=$ 0.383, respectively) between December 10, 2007 to October 31, 2011. Among these, DAEC was the most common pathotype, being detected in a similar proportion in cases $(8.4 \% ; 6 / 71)$ and controls $(8.4 \% ; 8 / 95)$ during infancy. Nonetheless, DAEC frequency was higher in controls aged $12-23$ months (0\% for cases vs. $7.1 \%$ for

Table 1 Diarrheagenic E. coli frequency in children with LSD enrolled between November, 2011 and November, 2012

\begin{tabular}{|c|c|c|c|c|c|c|c|c|c|}
\hline \multirow[t]{2}{*}{ Pathotype } & \multicolumn{3}{|l|}{ 0-11 months } & \multicolumn{3}{|l|}{$12-23$ months } & \multicolumn{3}{|l|}{ 24-59 months } \\
\hline & Cases $\boldsymbol{n}=104(\%)$ & Controls $\boldsymbol{n}=104(\%)$ & $\mathrm{P}$ & Cases $\boldsymbol{n}=120(\%)$ & Controls $\boldsymbol{n}=120(\%)$ & $P$ & Cases $\boldsymbol{n}=73(\%)$ & Controls $\boldsymbol{n}=73(\%)$ & $P$ \\
\hline EIEC & $1(1)$ & 0 & 1 & $1(0.8)$ & $1(0.8)$ & 1 & $3(4.1)$ & 0 & 0.245 \\
\hline DAEC & $2(1.9)$ & $2(1.9)$ & 1 & $1(0.8)$ & 0 & 1 & 0 & 0 & - \\
\hline EHEC & 0 & $1(1)$ & 1 & 0 & 0 & - & 0 & 0 & - \\
\hline
\end{tabular}


Table 2 Prevalence of DEC in children with MSD enrolled between December, 2007 and October, 2011

\begin{tabular}{|c|c|c|c|c|c|c|}
\hline \multirow[t]{2}{*}{ Pathotype } & \multicolumn{2}{|l|}{ 0-11 months } & \multicolumn{2}{|l|}{$12-23$ months } & \multicolumn{2}{|l|}{ 24-59 months } \\
\hline & Cases $\boldsymbol{n}=71(\%)$ & Controls $\boldsymbol{n}=95(\%)$ & Cases $\boldsymbol{n}=34(\%)$ & Controls $\boldsymbol{n}=42(\%)$ & Cases $\boldsymbol{n}=13(\%)$ & Controls $\boldsymbol{n}=17(\%)$ \\
\hline EIEC & $4(7.4)$ & $7(5.6)$ & $2(5.9)$ & $2(4.8)$ & $1(7.7)$ & $1(5.9)$ \\
\hline DAEC & $6(8.4)$ & $8(8.4)$ & 0 & $3(7.1)$ & $1(7.7)$ & $3(17.6)$ \\
\hline EHEC & $1(1.4)$ & $1(1)$ & 0 & 0 & 0 & $1(5.9)$ \\
\hline
\end{tabular}

No significant difference on frequency of diarrheagenic E. coli pathotypes was found between cases and controls ( $p>0.05)$

controls) and $24-59$ months $(7.7 \%$ for cases vs. $17.6 \%$ for controls). In contrast, EIEC was found more frequent in cases than in controls for all age strata, although no association was observed (Table 2). EHEC was only found in three samples; one sample from case (infant) and one from control (infant) and in one sample from a control aged 24-59 months.

\section{Discussion}

The contribution of EIEC, DAEC and EHEC on the burden of diarrheal diseases is currently unclear in most sub-Saharan countries, including Mozambique. This study, provides insight, to the importance of less studied pathotypes of DEC in rural context. Our data suggest that, despite the lower prevalence of EIEC, DAEC and EHEC in Manhiça community, the presence of those pathogens in asymptomatic children is of concern, considering that this group can play significant role as carriers and prone the outbreaks for susceptible individuals.

The finding of lower prevalence of EHEC, EIEC and DAEC between November 3, 2011 and November 2, 2012 can be explained by the majority of the cases enrolled in that period were LSD; in addition that many studies have associated EHEC and EIEC to outbreaks rather than endemic diarrhea [25-28]. Interestingly, we found a variation of EHEC, EIEC and DAEC frequencies between December 10, 2007 and October 31, 2011 which only enrolled cases of MSD and matched controls. In addition, we observed similar proportion of EIEC between cases and controls and a higher frequency of DAEC in controls than in cases, suggesting the role of asymptomatic children as carriers of these pathotypes in Manhiça community. Nevertheless, phenotyping and genotyping characterization of the isolates from cases and controls could provide detailed information about their genetic relatedness.

Previous reports on DEC prevalence in Maputo city (80 km from Manhiça) described a variable circulation of EIEC (0.3-21\%) in children with diarrhea [11, 14, 15], although not associated with the disease, whereas the detection of DAEC by phenotypic assay was significantly associated with diarrhea $(22.8 \%$ in cases vs. $11 \%$ in controls, $p<0.0001)$ [11]. It is unknow which factors are implicated in the variation of epidemiology of EIEC and DAEC between Manhiça (rural setting) and Maputo (urban setting). However, the difference found in the frequency of DAEC between the two studies may be explained by different detection methods used (PCR vs. phenotypic assay). DAEC was classically defined by the presence of a characteristic diffuse adherence (DA) pattern on HeLa and HEp-2 epithelial cells [7, 29]. However, as EPEC and other E. coli can also produce a similar result to DAEC in phenotypic assay (DA pattern) [29-31], these cell adhesion assays are being considered unsuitable for identification of DAEC [32]. Furthermore, the lower prevalence of DAEC can also be explained by the molecular detection of daaE (less conserved gene), which should be replaced by detection of recently described and highly conserved targets, such as afaC or daaD genes [32]. While some reports have associated DAEC with diarrhea [11, 33, 34], another ones have appointed for similar proportions of DAEC in case and controls [9] in alignment with our findings. In contrast with our findings, recent studies conducted in subSaharan Africa associated EIEC to diarrhea [35, 36]. At least, the lower circulation of EHEC is not surprisingly, since previous studies conducted in Mozambique revealed low circulation of this pathotype in Manhiça [5] and absence in Maputo city [11, 14, 15]. Nevertheless, the circulation of EHEC have been reported from a number of other locations in Africa, including Nigeria [37], and Uganda [38].

\section{Conclusions}

This study provides a first time insight into the prevalence of DEC, particular EIEC, DAEC, and EHEC in Manhiça district. Even though, previous studies have indicated that these pathotypes are less common in endemic childhood diarrhea, special attention should be given to their transmission dynamics (e.g. the role on sporadic or epidemic diarrhea) considering that the role of asymptomatic individuals as source of dissemination remains unknown.

\section{Abbreviations}

E. coli: Escherichia coli; DEC: Diarrheagenic Escherichia coli; EHEC: Enterohemorrhagic Escherichia coli; EIEC: Enteroinvasive Escherichia coli; DAEC: Diffusely adherent Escherichia coli; ETEC: Enterotoxigenic Escherichia coli; EPEC: Enteropathogenic Escherichia coli; EAEC: Enteroaggregative Escherichia coli; LSD: Less-severe diarrhea; MSD: Moderate-to-severe diarrhea; GEMS: The Global Enteric Multicenter Study; CISM: Manhiça Health Research Centre (Centro de Investigação em Saúde de Manhiça); SHCs: Sentinel health centers; 
MAC: MacConkey (MAC) agar; PCR: Polymerase Chain Reaction; DA: Diffuse Adherence

\section{Acknowledgements}

We thank the Manhiça Health District Authorities and the whole staff for supporting CISM in conducting the clinical and epidemiological studies in Health Facilities in Manhiça District. We thank the children who participated in this study and their families/caretaker, and special thank for the dedicated physicians, nurses, scientists, and CISM staff for their dedication and outstanding performance of clinical and laboratory study activities. We thank Nadia Boisen for the critical review of the manuscript.

\section{Authors' contributions}

IM and MG conceptualized the study. IM and PA participated in funding acquisition, resources and supervision. MG, NN, GM, DV, SM, SA and TN were responsible for data curation, investigation and validation. MG and IM performed the formal analysis, visualization and wrote the original draft. All authors read and approved the final manuscript.

\section{Funding}

The GEMS was funded by the Bill \& Melinda Gates Foundation and coordinated by the Center for Vaccine Development, University of Maryland School of Medicine under the grant (OPP1033572). CISM receives core funding from Spanish Agency for International Cooperation and Development (AECID - Agencia Española de Cooperacion Internacional para el Desarollo) and the Government of Mozambique. Marcelino Garrine has a scholarship from Calouste Gulbenkian Foundation "Fundação Calouste Gulbenkian" (grant number: 145278). The funders had no role in the study design, collection, analysis and interpretation of data, and manuscript writing.

\section{Availability of data and materials}

The datasets used and/or analyzed during the current study are available from the corresponding author on reasonable request.

\section{Ethics approval and consent to participate}

The E. coli strain collection analyzed in this study was isolated from the previously conducted GEMS study approved by the Mozambican National Bioethic Committee for Health (Comité Nacional de Bioética para Saúde IRB00002657) and by the Institutional Review Board of University of Maryland School of Medicine, Baltimore, MD, USA. Written informed consent were sought for mother or caretaker of eligible children.

\section{Consent for publication}

Not applicable.

\section{Competing interests}

The authors declare that they have no competing interests.

\section{Author details}

${ }^{1}$ Centro de Investigação em Saúde de Manhiça (CISM), Maputo,

Mozambique. ${ }^{2}$ Global Health and Tropical Medicine (GHTM), Instituto de Higiene e Medicina Tropical (IHMT), Universidade Nova de Lisboa (UNL), Lisbon, Portugal. ${ }^{3}$ Instituto Nacional de Saúde (INS), Ministério da Saúde, Maputo, Mozambique. ${ }^{4}$ ISGlobal, Hospital Clínic-Universitat de Barcelona, Barcelona, Spain.

\section{Received: 23 March 2020 Accepted: 28 August 2020}

Published online: 07 September 2020

\section{References}

1. Liu L, Oza S, Hogan D, Chu Y, Perin J, Zhu J, et al. Global, regional, and national causes of under-5 mortality in 2000-15: an updated systematic analysis with implications for the sustainable development goals. Lancet. 2016:388:3027-35.

2. Patzi-Vargas S, Zaidi MB, Perez-Martinez I, León-Cen M, Michel-Ayala A Chaussabel D, et al. Diarrheagenic Escherichia coli carrying supplementary virulence genes are an important cause of moderate to severe Diarrhoeal disease in Mexico. PLoS Negl Trop Dis. 2015;9:1-18.
3. Spano LC, Sadovsky ADI, Segui PN, Saick KW, Kitagawa SMS, Pereira FEL, et al. Age-specific prevalence of diffusely adherent Escherichia coli in Brazilian children with acute diarrhoea. J Med Microbiol. 2008;57:359-63.

4. Bonkoungou IJO, Haukka K, Österblad M, Hakanen AJ, Traoré AS, Barro N, et al. Bacterial and viral etiology of childhood diarrhea in Ouagadougou, Burkina Faso. BMC Pediatr. 2013;13:36.

5. Mandomando IM, Macete EV, Ruiz J, Sanz S, Abacassamo F, Valles X, et al. Etiology of diarrhea in children younger than 5 years of age admitted in a rural hospital of southern Mozambique. Am J Trop Med Hyg. 2007;76:522-7.

6. Croxen MA, Law RJ, Scholz R, Keeney KM, Wlodarska M, Finlay BB. Recent advances in understanding enteric pathogenic Escherichia coli. Clin Microbiol Rev. 2013;26:822-80.

7. Nataro JP, Kaper JB. Diarrheagenic Escherichia coli. Clin Microbiol Rev. 1998; 11:142-201.

8. Kaper JB, Nataro JP, Mobley HLT. Pathogenic Escherichia coli. Nat Rev Microbiol. 2004;2:123-40.

9. Mansan-Almeida R, Pereira AL, Giugliano LG. Diffusely adherent Escherichia coli strains isolated from children and adults constitute two different populations. BMC Microbiol. 2013;13:22.

10. Rajendran P, Ajjampur SSR, Chidambaram D, Chandrabose G, Thangaraj B, Sarkar R, et al. Pathotypes of diarrheagenic Escherichia coli in children attending a tertiary care hospital in South India. Diagn Microbiol Infect Dis. 2010;68:117-22

11. Rappelli P, Folgosa E, Letizia M, Leopoldo J, Pisanu C, Sidat M, et al. Pathogenic enteric Escherichia coli in children with and without diarrhea in Maputo, Mozambique. FEMS Immunol Med Microbiol. 2005;43:67-72.

12. Chissaque A, Deus ND, Vubil D, Mandomando I. The epidemiology of diarrhea in children under 5 years of age in Mozambique. Curr Trop Med Rep. 2018;5(3):115-24.

13. Nhampossa T, Mandomando I, Acacio S, Quintó L, Vubil D, Ruiz J, et al. Diarrheal disease in rural Mozambique: burden, risk factors and etiology of diarrheal disease among children aged 0-59 months seeking care at health facilities. PLoS One. 2015;10:12-23.

14. Sumbana J, Taviani E, Manjate A, Paglietti B, Santona A, Mauro M. Genetic determinants of pathogenicity of Escherichia coli isolated from children with acute diarrhea in Maputo, Mozambique. J Infect Dev Ctries. 2015;9: 661-4.

15. Santona S, Diaz N, Fiori PL, Francisco M, Sidat M, Cappuccinelli $P$, et al. Genotypic and phenotypic features of enteropathogenic Escherichia coli isolated in industrialized and developing countries. J Infect Dev Ctries. 2013; 7:214-9.

16. Kotloff $\mathrm{KL}$, Nataro JP, Blackwelder WC, Nasrin D, Farag TH, Panchalingam S, et al. Burden and aetiology of diarrhoeal disease in infants and young children in developing countries (the global enteric multicenter study, GEMS): a prospective, case-control study. Lancet. 2013;382:209-22.

17. Kotloff KL, Nasrin D, Blackwelder WC, Wu Y, Farag T, Panchalingham S, et al. The incidence, aetiology, and adverse clinical consequences of less severe diarrhoeal episodes among infants and children residing in low-income and middle-income countries: a 12-month case-control study as a follow-on to the global enteric multicenter study (GEMS). Lancet Glob Health. 2019;7: e568-84.

18. Alonso P, Saúte F, Aponte J, Gómez-Olivé F, Nhacolo A, Thomson R, et al. Manhiça DSS, Mozambique. In Population and Health in Developing Countries Volume 1. Population, Health, and Survival at INDEPTH Sites. 1st edition. Edited by: INDEPTH. Ottawa: International Development Research Centre (IDRC); 2002. p. 189-95.

19. Sacoor C, Nhacolo A, Nhalungo D, Aponte JJ, Bassat Q, Augusto O, et al. Profile: Manhica Health Research Centre (Manhica HDSS). Int J Epidemiol. 2013:42:1309-18.

20. Kotloff KL, Blackwelder WC, Nasrin D, Nataro JP, Farag TH, van Eijk A, et al. The Global Enteric Multicenter Study (GEMS) of diarrheal disease in infants and young children in developing countries: epidemiologic and clinical methods of the case/control study. Clin Infect Dis. 2012; 55(Suppl 4):S232-45.

21. Panchalingam S, Antonio M, Hossain A, Mandomando I, Ochieng B, Oundo J, et al. Diagnostic microbiologic methods in the GEMS-1 case/control study. Clin Infect Dis. 2012;55(Suppl 4):S294-302.

22. Frankel G, Giron JA, Valmassoi J, Schoolnik GK. Multi-gene amplification: simultaneous detection of three virulence genes in diarrhoeal stool. Mol Microbiol. 1989;3:1729-34. 
23. Persson S, Olsen KEP, Scheutz F, Krogfelt KA, Gerner-Smidt P. A method for fast and simple detection of major diarrhoeagenic Escherichia coli in the routine diagnostic laboratory. Clin Microbiol Infect. 2007;13:516-24.

24. Vidal M, Kruger E, Durán C, Levine M, Prado V, Toro C, et al. Single multiplex PCR assay to identify simultaneously the six categories of Diarrheagenic Escherichia coli associated with enteric infections. J Clin Microbiol. 2005;43: 5362-5.

25. Masaki OM, Kamigaki T, Mimura S, Nakashima K, Ogami T. An enterohaemorrhagic Escherichia coli outbreak spread through the environment at an institute for people with intellectual disabilities in Japan in 2005. West Pac Surveill Response J. 2019:10:14-21.

26. Kanayama A, Yahata Y, Arima Y, Takahashi T, Saitoh T, Kanou K, et al. Enterohemorrhagic Escherichia coli outbreaks related to childcare facilities in Japan, 2010-2013. BMC Infect Dis. 2015;15:539.

27. Escher M, Scavia G, Morabito S, Tozzoli R, Maugliani A, Cantoni S, et al. A severe foodborne outbreak of diarrhoea linked to a canteen in Italy caused by enteroinvasive Escherichia coli, an uncommon agent. Epidemiol Infect. 2014;142:2559-66

28. Zhou X, Xia W, Tu J, Xue L, Ni X. Molecular characterisation of enteroinvasive Escherichia coli 0136:K78 isolates from patients of a diarrhoea outbreak in China. Indian J Med Microbiol. 2015;33:528-32.

29. Scaletsky IC, Silva ML, Trabulsi LR. Distinctive patterns of adherence of enteropathogenic Escherichia coli to HeLa cells. Infect Immun. 1984;45:5346.

30. Hernandes RT, Elias WP, Vieira MAM, Gomes TAT. An overview of atypical enteropathogenic Escherichia coli. FEMS Microbiol Lett. 2009:297:137-49.

31. Nataro JP, Scaletsky IC, Kaper JB, Levine MM, Trabulsi LR. Plasmid-mediated factors conferring diffuse and localized adherence of enteropathogenic Escherichia coli. Infect Immun. 1985;48:378-83.

32. Meza-Segura M, Estrada-Garcia T. Diffusely adherent Escherichia coli. In: Torres AG, editor. Escherichia coli in the Americas. Switzerland: Springer International Publishing; 2016. p. 125-47. https://doi.org/10.1007/978-3-31945092-6 6.

33. Scaletsky ICA, Aranda KRS, Souza TB, Silva NP. Adherence factors in atypical enteropathogenic Escherichia coli strains expressing the localized adherence-like pattern in HEp-2 cells. J Clin Microbiol. 2010;48:302-6.

34. Lozer DM, Souza TB, Monfardini MV, Vicentini F, Kitagawa SS, Scaletsky ICA et al. Genotypic and phenotypic analysis of diarrheagenic Escherichia coli strains isolated from Brazilian children living in low socioeconomic level communities. BMC Infect Dis. 2013;13:418.

35. Platts-Mills JA, Amour C, Gratz J, Nshama R, Walongo T, Mujaga B, et al. Impact of rotavirus vaccine introduction and Postintroduction etiology of diarrhea requiring hospital admission in Haydom, Tanzania, a rural African setting. Clin Infect Dis. 2017;65:1144-51.

36. Iturriza-Gómara M, Jere KC, Hungerford D, Bar-Zeev N, Shioda K, Kanjerwa O, et al. Etiology of diarrhea among hospitalized children in Blantyre, Malawi, following rotavirus vaccine introduction: a case-control study. J Infect Dis. 2019;220:213-8

37. Okeke IN, Lamikanra A, Steinrück H, Kaper JB. Characterization of Escherichia coli strains from cases of childhood diarrhea in provincial southwestern Nigeria. J Clin Microbiol. 2000;38:7-12.

38. Majalija S, Segal H, Ejobi F, Elisha BG. Shiga toxin gene-containing Escherichia coli from cattle and diarrheic children in the pastoral systems of southwestern Uganda. J Clin Microbiol. 2008;46:352-4.

\section{Publisher's Note}

Springer Nature remains neutral with regard to jurisdictional claims in published maps and institutional affiliations.

Ready to submit your research? Choose BMC and benefit from:

- fast, convenient online submission

- thorough peer review by experienced researchers in your field

- rapid publication on acceptance

- support for research data, including large and complex data types

- gold Open Access which fosters wider collaboration and increased citations

- maximum visibility for your research: over $100 \mathrm{M}$ website views per year

At BMC, research is always in progress.

Learn more biomedcentral.com/submissions 